\title{
The Trade-Off Between Technology Deployment and Enviro-Economic Benefits in Smart Buildings
}

\author{
Jean-Nicolas Louis, Eva Pongrácz \\ University of Oulu \\ Thule Institute, NorTech Oulu \\ Oulu, Finland \\ e-mails: jean-nicolas.louis@oulu.fi, eva.pongracz@oulu.fi
}

\author{
Kauko Leiviskä \\ University of Oulu \\ Control Engineering Laboratory \\ Oulu, Finland \\ e-mail: kauko.leiviska@oulu.fi
}

\begin{abstract}
Smart grids are meant to reach multiple goals such as leveling the electricity demand profile, reducing electricity consumption and increasing the energy efficiency of the electrical grid. Smart buildings play an important role in achieving these goals. With an increased number of measuring and controlling tools, new problems also arise, such as their economic and environmental impacts, juxtaposed to the levels of savings achieved by them. This research investigated the impact of home automation on electricity consumption, related $\mathrm{CO}_{2}$ emissions and costs. A smart building model with its appliances and different number of inhabitants was used along with eight electricity contracts and four different technology systems deployed. The results showed that a fully deployed automation system may be counterproductive, as the electricity need of the system may exceed the savings achieved by it. Therefore, a careful selection of the appliances to be used should be performed.
\end{abstract}

Keywords-Energy consumption; Load management; Environmental factors; Building automation; Economic

\section{INTRODUCTION}

The development of the electricity infrastructure toward smart grids brings new technological features to homes, in order to monitor and control energy consumption. Home energy management system (HEMS) is a key component in the development of smart buildings that will control the electricity consumption in the house. Smart meters' deployment represents the first step toward enhancing home automation and has reached a point where most of the residential sector is currently monitored at least on an hourly basis. Technologies have been developed also for detailing the electricity usage of smart plugs, which are devices that transmit wirelessly the electricity consumption data of the device connected to it. An additional technology associated with smart plugs is an in-home display, which works as an energy interface for the end-user that can potentially remotely control appliances, and integrates user preferences. In

The Thule Institute Research Programme is acknowledged for financing this research. parallel to the technology development and implementation, economic tools are also being developed to make dynamic pricing available for residential consumers. The expectation is that smart buildings will contribute to achieving the goals of reducing electricity consumption and $\mathrm{CO}_{2}$ emissions, and flattening the electricity load profile by shifting the demand. Previous research has shown that the implementation of control technology alone can reach a reduction of $\mathrm{CO}_{2}$ emissions by $12 \%$ for an average-sized household [1]. However, the home energy management system also requires economic investments and, furthermore, the manufacture and use-phase of the devices has environmental impacts as well. It has been previously highlighted that expectations on smart homes lie in the reduction of energy consumption and decrease in related to the energy consumption [2]. Our earlier research indicated that the economic and $\mathrm{CO}_{2}$ savings achieved through these smart devices do not necessarily compensate for the investment, especially in terms of energy savings vs. energy consumption of control devices [3]. This research looks at the trade-off between technology deployment and enviro-economic benefits of home automation. The environmental impact assessment is based on the results of an LCA study and on hourly emission factors that are calculated based on the electricity mix of Finland. The economic impacts will be assessed by balancing the lifecycle energy consumption of smart devices with the achieved electricity savings of the home in the use phase. In addition, three economic scenarios will be investigated; a fixed price -based billing, the time of use pricing system, and dynamic pricing. These will be assessed using a simulation tool that generates electricity consumption profiles for individual detached houses. Ultimately, the research intends to answer the questions: what is the balance between the environmental and economic impacts and benefits of home automation, and is there a trade-off between technology deployment and enviro-economic benefits in smart buildings.

\section{Related Research}

Research on modelling electricity consumption in the residential sector are numerous [4]-[6] and have been considered when creating a model for generating electricity 
consumption in households in Finland [7]. The model on which this study is based showed that home automation may decrease the electricity consumption, however, two challenges may surface: the degree of technology to be implemented for reaching the goals set for smart buildings and the willingness of the end-user to participate actively in improving electricity consumption behaviour.

$\mathrm{CO}_{2}$ emission levels are calculated dynamically for each hour in the simulation and are based on the fuel type that is used as a primary source for generating electricity [8]. Previous research looked at the environmental impact of smart buildings and has shown that most of the impacts occur during the use phase of the technology [3].

Looking at the factors affecting end-users, Koksal et al. [9] investigated the relationship between load, cost and emissions and concluded that these factors are inter-dependent, and also present similar profiles. In this matter, these factors applied to smart buildings for electricity optimization need to be researched thoroughly for understanding the impact of smart buildings on electricity consumption profiles, on $\mathrm{CO}_{2}$ emissions and on household's economy.

\section{Smart Building Control}

The building considered in our simulation includes 21 different appliances that can be multiplied to match the needs of every inhabitant in the house. It includes washing machine, dish-washer, electric hubs, kettle, oven, coffee maker, microwave, toaster, waffle maker, fridge, television, laptop, shaver, hair dryer, stereo, vacuum cleaner, telephone charger, iron, radio, electric heater, and sauna. The model for generating actions has been described in [7]. The lighting system includes incandescent and low consumption bulbs and their number is dependent on the number of inhabitants as well as the surface area of the house. The heating/cooling system is assumed to be provided by the district heating system and is therefore not included in the simulation.

The HEMS of the house is price-driven and, therefore, postponing or advising postponing an action is going to be made based on current and forecasted prices of electricity. Four types of technology deployment levels are considered: No smart meter as the reference level (1), installation of a smart meter used for billing purposes (2), a smart meter with the possibility to retrieve feedbacks to end-users and advice them to take direct actions into consideration (3), and the full HEMS implementation where appliances can be controlled automatically (4). Each of the technology levels has been implemented in the simulation tool. Levels 2 and 3 integrate a smart meter with a display, which has a power consumption of $20 \mathrm{~W}$, while level 4 integrates also smart plugs. Each smart plug has a power rating of $4 \mathrm{~W}$ and it is assumed that there are as many smart plugs as appliances present in the house. The number of appliances is directly dependent on the number of inhabitants.

Understanding end-users' motivation and their level of comprehension towards smart technology will help deploying the right technology. Nevertheless, the segmentation of end-users is multiple and a user may be defined following different characteristics that will influence his/her willingness to adopt a decision. Therefore, users can be categorised depending on their level of technology understanding, their willingness to pay more for getting greener energy, modifying their behaviour, letting in-house control system to manage their energy or having the HEMS controlled by a $3^{\text {rd }}$ party [10]. Therefore, end-users response was split into three distinct categories, established as "green", "orange" and "brown" users, in this research. Each end-user category presents a different level of positive response depending on the recommendation made by the smart meter, in case of configuration (3), or the HEMS in configuration (4) is in place. While the system may advice to postpone or reduce an action, the end-user may decide otherwise. Therefore, a "brown" user will have a $30 \%$ positive response, an "orange" user will have a $50 \%$ positive response, and a "green" user will have a $70 \%$ response. The positive response is further modulated by the bias of the current and the historical electricity consumption level. In this research, our focus was set on "green" users.

In case of scenario 3, only end-user preferences were used. The end-user has the choice of either not postponing an action, postponing it for a short-term of one hour, or postponing it for a longer time that can reach three hours. In case where the HEMS is fully deployed, the initiative for postponing an action is directly taken by the HEMS system. Actions that can be postponed are defined in the model appliance specifically. Therefore, characteristics for each appliance are considered by the control system.

\section{Pricing System}

The price of electricity varies in the transmission and distribution networks. In the Nordic countries, the price of electricity is subject to a tendering process where each electricity producer put bids on the market. The bidding system closes at $18 \mathrm{pm}$ and the hourly prices are fixed for the next $24 \mathrm{~h}$. Furthermore, price signals are sent to energy producers when the consumption or the production of electricity is too high, known as up and down regulating prices. Dynamic pricing on the distribution grid is provided by the Transmission System Operator (TSO) and is appearing and available for individual users. Therefore, three types of contracts are available for households: the fixed price, the time of use tariffs, and the spot price system.

\section{A. Fixed price and Time of Use tariffs}

Fixed price and Time of Use (ToU) tariffs vary depending on the electricity retailer and the contract selected within one energy company. As a base line, tariffs given by Oulun Energia Oy have been integrated into the simulation tool.

TABle I. Price Variation for the ToU and FiXed Price tariffs [11]

\begin{tabular}{|c|c|c|c|c|}
\cline { 3 - 5 } \multicolumn{2}{c|}{} & $\begin{array}{c}\text { Wind } \\
\text { Power } \\
{[\mathbf{c t s} € / \mathbf{k W h}]}\end{array}$ & $\begin{array}{c}\text { Bio-Energy } \\
{[\mathbf{c t s} € / \mathbf{k W h}]}\end{array}$ & $\begin{array}{c}\text { Mixed En- } \\
\text { ergy [cts } € / \\
\text { kWh] }\end{array}$ \\
\hline \multirow{2}{*}{ ToU } & $\mathbf{7 - 2 2}$ & 6.87 & 6.72 & 6.57 \\
\cline { 2 - 5 } & $\mathbf{2 2 - 7}$ & 6.33 & 6.18 & 6.03 \\
\hline \multicolumn{2}{|c|}{ Fixed Price } & 7.04 & 6.89 & 6.74 \\
\hline
\end{tabular}


The ToU tariff works on a day and night tariff where the time zones between $7 \mathrm{am}$ and $10 \mathrm{pm}$ are used. Also, ToU tariffs include seasonal variations between summer and wintertime. Finally, differences of electricity prices occur in three different contracts: the mix energy, the electricity produced from biomass, and the electricity produced from wind power. The price range varies from $6.74 \mathrm{cts} € / \mathrm{kWh}$ for the mixed energy, $6.89 \mathrm{cts} € / \mathrm{kWh}$ for the bio-energy, to $7.04 \mathrm{cts} € / \mathrm{kWh}$ for the electricity produced from wind power and are detailed in Table 1.

Other tariffing systems are available but have been ignored, as they were not giving any added information to the existing contracts.

\section{B. Unlimited spot price for individuals}

Dynamic pricing on the distribution grid is appearing and available to individual consumers. Dynamic pricing on the distribution grid is set as a function of a two-price system, depending on up- and down-regulation. The hourly pricing $\mathrm{P}_{\mathrm{h}}$ is therefore given to end-users as a component of the spot price and local taxes.

$$
P_{h}=P_{s} \cdot(1+V A T)+P_{d}+T_{e}
$$

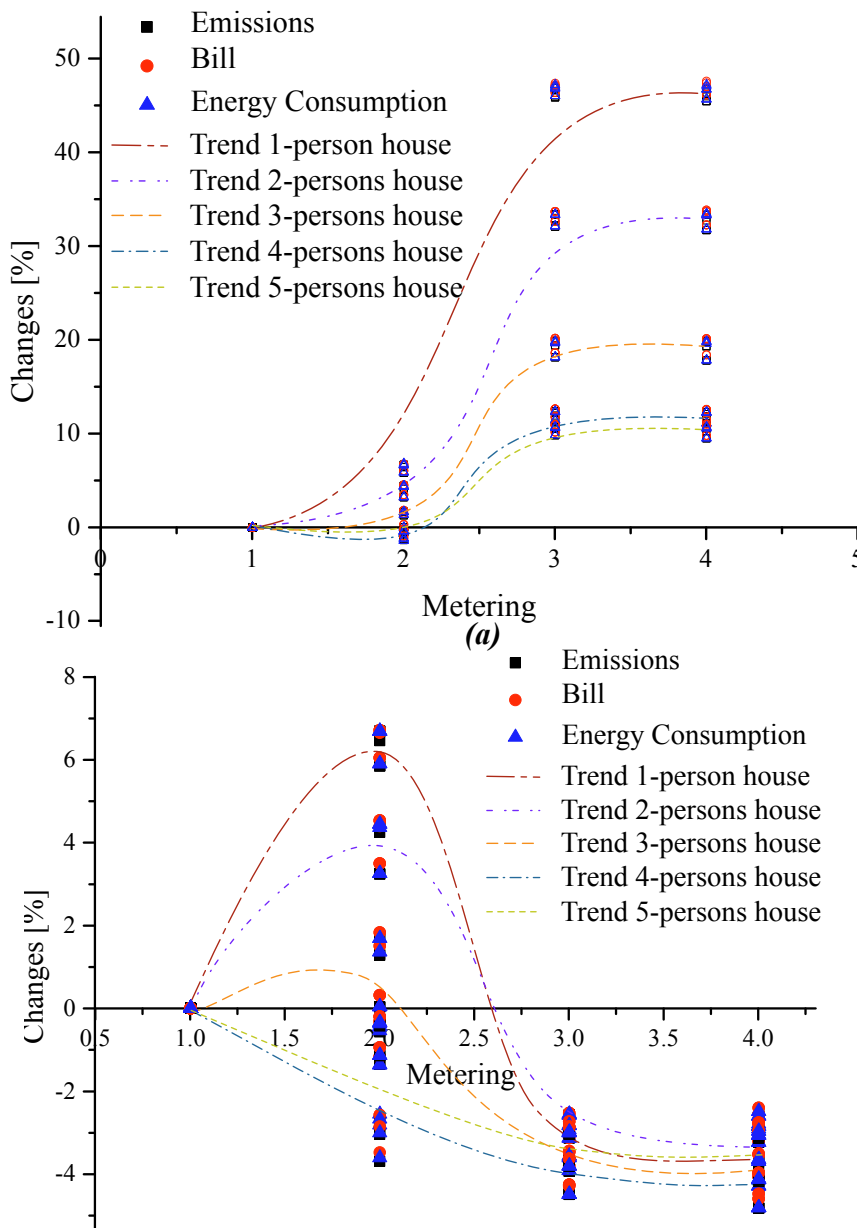

(c)
Where $\mathrm{P}_{\mathrm{s}}$ is the spot price [€cts/kWh], VAT is the value-added tax [\%], $\mathrm{P}_{\mathrm{d}}$ is the distribution price [€cts/kWh], and $\mathrm{T}_{\mathrm{e}}$ is the electricity tax [€cts/kWh].

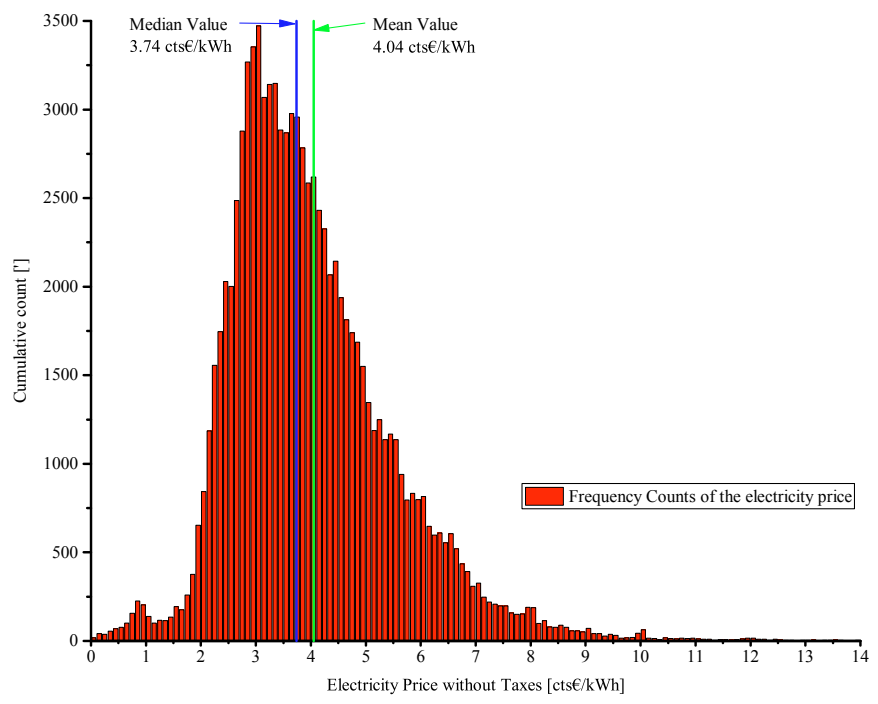

Figure 1. Cumulative frequency of electricity spot prices during the period 2004 to 2014 as applied to individual end-users.
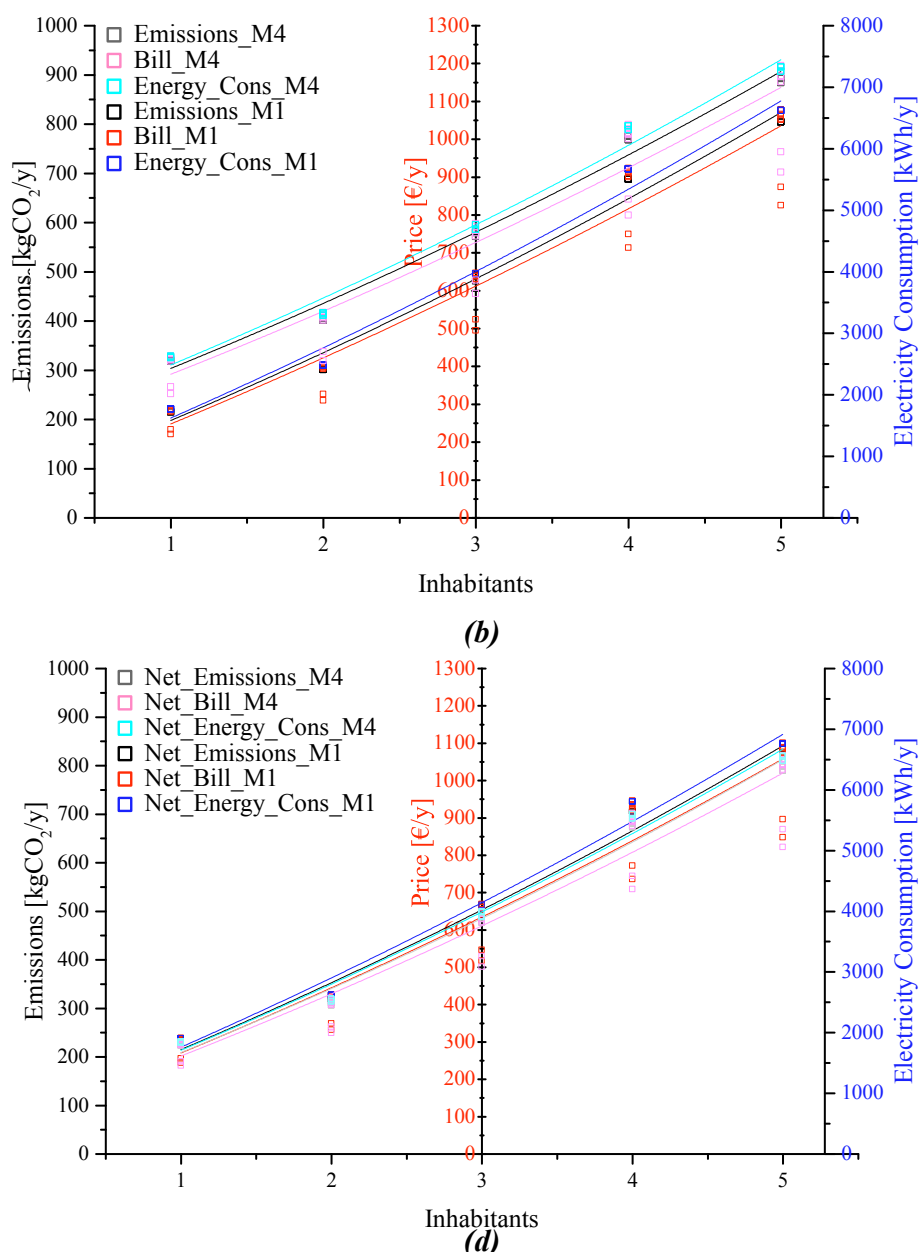

Figure 2. Variation of the price, the electricity consumption and the $\mathrm{CO}_{2}$ emissions when accounting the electricity consumption from the home energy management system when accounting the electricity used by the technology deployed (a), and depending on the number of inhabitants (b). Net benefits of the HEMS depending on the technology deployed (c), and on the number of inhabitants (d). 
Tax levels vary on a yearly basis, while the distribution price varies on a monthly basis. Data can be collected through the Energy Market Authority [12]. On top of the spot price, energy companies can introduce other variables such as an opening price $\mathrm{P}_{0}$, which sets a minimum level of electricity price that the consumer must pay for every kilowatt-hour consumed. A starting price of $0.25 \mathrm{cts} € / \mathrm{kWh}$ is used in this research. Therefore, the hourly price $\mathrm{Ph}, \mathrm{h}$ set to end-users is:

$$
P_{h, h}=P_{o}+P_{h}
$$

One of the issues with the unrestricted spot price system is that end-users are subject to the variation of the electricity price where a ceiling price does not occur. During the period from 2004 to 2014, the highest price on the distribution network was $140 \mathrm{cts} € / \mathrm{kWh}$, on the $22^{\text {nd }}$ of February 2010 at $7 \mathrm{am}$. High values of electricity price do not occur very often, as Fig. 1 suggests, but it can become a threat to end-users who do not pay attention to the electricity price. Sampling the electricity spot price from the period 2004 to 2014 highlighted that the mean price of electricity is set around $4.04 \mathrm{cts} € / \mathrm{kWh}$, and the median electricity price is around
$3.74 \mathrm{cts} € / \mathrm{kWh}$. Therefore, energy companies have introduced a tariffing system where the hourly price can be restricted for avoiding unexpected extremely high prices.

\section{Limited spot price for individuals}

In the perspective of levelling the electricity price by considering both the interests of the consumer and the Distribution System Operator (DSO), lower and higher safeguards are set to limit the price of the electricity, which can be applied to end-users. It could be set for instance that no negative price may ever appear on the distribution network and thus the minimum price of the electricity is set to 1 cts€. For example the strategy taken by Oulun Energia Oy is to limit the spot price $\mathrm{P}_{\text {s }}$ to $8.6 \mathrm{cts} € / \mathrm{kwh}$ but, in exchange, the end-user must pay a fixed fee of $5 € /$ month [11].

\section{Results}

The results indicate that there is a disparity between the number of inhabitants in the house, the type of electricity contract and the technology deployed in the house. The results are presented for two cases: (1) all electricity
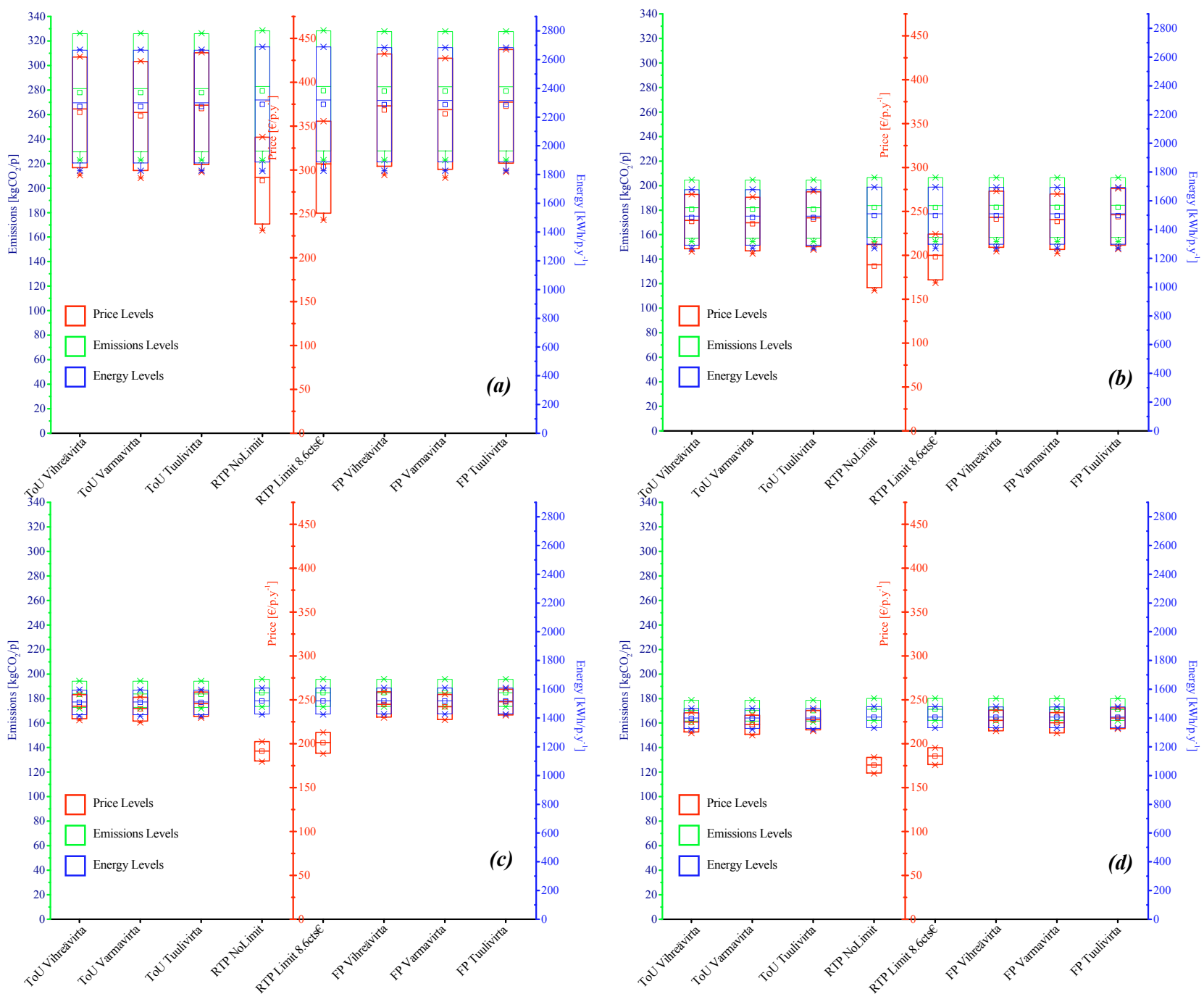

Figure 3. Impact of the type of contract selected by house for 1 (a), 2 (b), 4 (c), and 5 (d) persons house on the electricity consumption, the $\mathrm{CO}_{2}$ emission levels and the electricity bill when considering the power consumption of the added technology. Each variable within each contract is expressed per inhabitant, where contracts integrate the four types of technology deployment as defined in Fig. 2 (a) and (c) 
consumption is taken into consideration including the home energy management system (Figs. 2a and b), and (2) only the benefits are taken into account (Figs. 2c and d). Figs. $2 b$ and $d$ illustrate the results of the influence of technology depending on the number of inhabitants in the house. In the case where the electricity from the HEMS is taken into considerations, none of the evaluated factors (Environmental, Economical, and Energy) encounter a positive impact when using HEMS. Nevertheless, HEMS has a positive impact on the electricity consumption as Fig. 2b suggests but the savings do not counterbalance the HEMS's electricity consumption. The potential to offset the electricity consumption from the HEMS decreases when the number of inhabitants increases as Fig. 2 suggests. While the electricity consumption rises by $46 \%$ on average for a 1-person house, it increases by $10 \%$ for a 5-persons house on average. Nonetheless, Fig. $2 \mathrm{~b}$ and d look only at the full deployment of a HEMS system and intermediary solutions are not represented. A similar trend can be observed for the two other studied factors; the $\mathrm{CO}_{2}$ emission levels and the impact on the bill.

The change of energy consumption, electricity bill, and $\mathrm{CO}_{2}$ emissions expressed as a percentage difference with the basic installation (regular electricity meter) is emphasized in Fig. 2a and $\mathrm{c}$ for each type of technology deployed. While all households can see their consumption and emissions grow depending on the type of metering system in the house, the net impact of the HEMS increases from $+10 \%$ for a 5 -persons house, to $+50 \%$ for a 1-person house. Although the full deployment of HEMS is not beneficial for any of the number of inhabitants, it appears that for households of 4 persons and more, the smart meter retrieving information only (metering 2) might affect the results positively by decreasing the impact by $2 \%$. Technology implementation does have a positive effect, as shown in Fig. 2c; the higher number of inhabitants, the more effect the system will have on the electricity consumption level.

Another perspective of the modelled system was the impact of the pricing system on the household. Fig. 3 illustrates the related electricity consumption, $\mathrm{CO}_{2}$ emission levels and the impact on the electricity bill for each type of contract. In order to have a similar base of comparison, each of the variables are expressed per inhabitant. The variables given for the 4 types of households are 1, 2, 4, and 5 inhabitants. Regardless of the number of inhabitants, the trend suggests that dynamic pricing represents the most economical variant for end-users, with or without an upper limiting threshold. Nonetheless, the spot price system with limitation does not seem to be adjusted well enough to compensate for the few hours in a year when the spot price goes over the delimited boundary. The other contracts present slight differences per inhabitant but not as distinct as the two hourly pricing contracts. Again, the more inhabitants are in the house, the lowest deviation there is between the different types of technology deployed in the house. As well, the greater the number of inhabitants, the smaller the impact.

\section{CONCLUSION}

This research presented the trade-off between the benefits and impacts of home automation in residential buildings. Five inhabitant types and four different technology deployment levels were simulated. Simulations were run for 1-5 inhabitants and the number of appliances as well as the surface area of the house varied with the number of inhabitants. The study considered eight electricity contracts split into three categories: fixed price, time of use contract, and real time pricing system. Finally, hourly $\mathrm{CO}_{2}$ emission levels were calculated based on the fuel used for electricity generation.

The simulations indicated that integrating a large number of smart plugs is counter-productive in terms of energy and cost savings, as their electricity consumption and related impacts offset the benefits achieved by them. Only in case of households with four or more inhabitants did result in a 2 $\%$ positive impact. Therefore, efforts should be made on the development of energy efficient HEMS for uncovering the true benefit of such system.

\section{REFERENCES}

[1] J.-N. Louis, A. Caló, and E. Pongrácz, "Smart houses for energy efficiency and carbon dioxide emission reduction," ENERGY 2014 : The Fourth International Conference on Smart Grids, Green Communications and IT Energy-aware Technologies, pp. 44-50, Apr. 2014.

[2] N. Balta-Ozkan, B. Boteler, and O. Amerighi, "European smart home market development: Public views on technical and economic aspects across the United Kingdom, Germany and Italy," Energy Research \& Social Science, vol. 3, pp. 65-77, Sep. 2014.

[3] J.-N. Louis, A. Caló, K. Leiviskä, and E. Pongrácz, "Environmental Impacts and Benefits of Smart Home Automation: Life Cycle Assessment of Home Energy Management System," presented at the MATHMOD 2015 - 8th Vienna International Conference on Mathematical Modelling, Vienna, Austria, 2015, In Press. pp. 1-6.

[4] J. V. Paatero and P. D. Lund, "A model for generating household electricity load profiles," Int. J. Energy Res., vol. 30, no. 5, pp. 273290, 2006

[5] N. Good, L. Zhang, A. Navarro-Espinosa, and P. Mancarella, "High resolution modelling of multi-energy domestic demand profiles," Applied Energy, vol. 137, no. C, pp. 193-210, Jan. 2015.

[6] D. P. Jenkins, S. Patidar, and S. A. Simpson, "Synthesising electrical demand profiles for UK dwellings," Energy \& Buildings, vol. 76, pp. 605-614, Jun. 2014.

[7] J.-N. Louis, A. Caló, K. Leiviskä, and E. Pongrácz, "Home Automation for a sustainable living - Modelling a detached house in Northern Finland," Proceedings of the 7th International Conference on Energy Efficiency in Domestic Appliances and Lighting EEDAL'13, pp. 561571, Sep. 2013.

[8] J.-N. Louis, A. Caló, K. Leiviskä, and E. Pongrácz, "A Methodology for Accounting the $\mathrm{CO} 2$ Emissions of Electricity Generation in Finland," International Journal on Advances in Intelligent Systems, vol. 8, no. 3, pp. 560-571, Dec. 2014.

[9] M. A. Koksal, I. H. Rowlands, and P. Parker, "Energy, cost, and emission end-use profiles of homes: An Ontario (Canada) case study," Applied Energy, vol. 142, no. C, pp. 303-316, Mar. 2015.

[10] P. Goncalves Da Silva, S. Karnouskos, and D. Ilic, "A Survey Towards Understanding Residential Prosumers in Smart Grid Neighbourhoods," presented at the 3rd IEEE PES Innovative Smart Grid Technologies Europe (ISGT Europe), Berlin, Germany, 2012, pp. 1-8.

[11] Oulun Sähkönmyynti Oy, Ed., Pohjoista voimaa sähkösopimus. [Online]. Available: http://goo.gl/ux5uGL. [Accessed: Feb-2015].

[12] Energy Market Authority. [Online]. Available: http://goo.gl/d169aJ. [Accessed: Feb-2015]. 